\section{HIPERFICCIÓN CONSTRUCTIVA EN EL TERCER ENTORNO}

\author{
Manuel A. Broullón-Lozano \\ Universidad Complutense de Madrid \\ ORCID iD: https://orcid.org/0000-0003-0840-474X \\ mabroullon@ucm.es \\ José Manuel Romero Santos \\ Universidad de Sevilla \\ ORCID: https://orcid.org/0000-0002-8354-5182 \\ josromsan5@alum.us.es
}

Cómo citar este artículo/Citation: Broullón-Lozano, Manuel A. y Romero Santos, José Manuel. (2020). Hiperficción constructiva en el tercer entorno. Arbor, 196 (798): a582. https://doi. org/10.3989/arbor.2020.798n4006

Recibido: 25 mayo 2020. Aceptado: 31 octubre 2020.

RESUMEN: Los modelos de escritura están experimentando grandes transformaciones como consecuencia de la revolución tecnológica contemporánea. Aunque los cibertextos y los hipertextos no son realidades exclusivas de la cultura digital, pues se dan en contextos culturales precedentes, aportan formas de pensamiento alternativas, que pasan por implicaciones epistemológicas -el pensamiento en red-, estéticas -reformulación de la autoría- y éticas -exigen un compromiso por parte del receptor. En este trabajo se abordará dicha coyuntura comparando las escrituras literarias Hypertext Hotel (1992) y Leyenda mayor de lan Curtis (2017) con las escrituras audiovisuales +101 (2012) y Quién lo impide (2018), con el objetivo de comprender las transformaciones que suponen tanto en la experiencia estética como en el campo cultural digital. Para ello, se empleará una metodología comparatista que tenga en cuenta las concomitancias entre las dos series de escrituras.

PALABRAS CLAVE: Hiperficción constructiva; literatura comparada; escrituras multimodales; escrituras colaborativas.

\section{CONSTRUCTIVE HYPERFICTION IN THE THIRD ENVIRONMENT}

Copyright: (C) 2020 CSIC. Este es un artículo de acceso abierto distribuido bajo los términos de la licencia de uso y distribución Creative Commons Reconocimiento 4.0 Internacional (CC BY 4.0).

ABSTRACT: Writing models are undergoing major transformations as a result of the contemporary technological revolution. Although cybertexts and hypertexts as realities are not exclusive to digital culture, since they were present in previous cultural contexts, the truth is they provide alternative ways of thinking involving implications that are epistemological (network thinking), aesthetic (reformulation of authorship), and ethical (requiring an active and reflective commitment on the part of the recipient). In this work, such a scenario will be approached comparing the literary writings Hypertext Hotel (1992) and Leyenda mayor de lan Curtis (2017) with the audiovisual writings +101 (2012) and Quién lo impide (2018), with the aim of understanding the transformations they represent both in the aesthetic experience and in the digital cultural field. To do this, a comparative methodology will be used that takes into account the concomitances between the two series of writings.

KEYWORDS: Constructive hyperfiction; comparative literature; multimodal writing; collaborative writings. 


\section{MUTACIONES DE LAS ESCRITURAS ANTE EL TERCER ENTORNO}

El aprendizaje y enseñanza de la escritura creativa debe asumir en la actualidad el reto de la experimentación con formatos, soportes y técnicas cada vez más diversos. No solo la recopilación de materiales o la nolinealidad del procesador de texto digital, sino sobre todo el uso extensivo de distintas unidades significantes combinadas sobre la misma superficie-imágenes, sonidos, textos lingüísticos, registros, documentos, etc.-, propician cada vez con más frecuencia fenómenos de hibridación, a partir de la condición del texto resultante como escritura heterogénea.

De entre todas las posibilidades que podrían plantearse, en este trabajo nos interesan aquellas que suscitan una convergencia contrastiva, cuando no conflictiva. Conveniente recordar, a pesar de todo, que este tipo de prácticas de mixtificación «hipertextual» (Landow, 2006), «inter-» O «trans-medial» (SánchezMesa Martínez, 2019), «hiper-medial» y «re-medial» (Bolter y Grusin, 2011) o "trans-discursiva» (Barroso Villar, 2007) no son un fenómeno exclusivo de nuestro tiempo. Todo cambio introduce profundas mutaciones en la «forma simbólica» (Cassirer, 1998) con la que los sujetos somos capaces de interactuar en sociedad, cualquiera que sea la manera elegida: desde la palabra pronunciada hasta el bit electrónico. A partir de la segunda mitad del pasado siglo, las expresiones artísticas y culturales han ido incorporando los nuevos descubrimientos tecnológicos, cuyo uso se ha ido asentando en el espacio social. Así es que en ese espacio social se ha producido un cambio del marco cultural o frame, tal y como lo denomina Georges Lakoff (2007). Dicho marco cultural no se limita al cambio de unos significantes por otros, sino que atañe a la forma simbólica misma: los modos de pensar, de interactuar, de definirnos y de gestionar el mundo de la vida (Lebenswelt).

No en vano, Marshall McLuhan definió la técnica como «prótesis» del cuerpo:

Hoy, tras más de un siglo de tecnología eléctrica, hemos extendido nuestro sistema nervioso central hasta abarcar todo el globo, aboliendo el tiempo y el espacio, al menos en lo que a este planeta se refiere.

[...]. Cualquier extensión, sea de piel, de la mano o del pie, afecta a todo el complejo psíquico y social" (McLuhan, 1996: 25-26).

Asistimos al «horizonte del surgimiento y desarrollo de formas más allá del hombre» u "horizonte de transhumanización» (Vázquez Medel, 2003: 29), en el que la temporalidad se acelera, y los espacios -em- píricos o imaginarios- se interconectan, configurando trayectos y dibujando posibles geografías. También las asociaciones de ideas y las identidades, por medio de operaciones de montaje, se vuelven más complejas.

El «espacio social», por tanto, puede definirse como un tercer entorno (Echeverría, 2004), en donde la conciencia y el cuerpo humanos, vía tecnológica, se han extendido desde la polis -ciudad de los cuerposhasta la telépolis -imagen simbólica que fluye por el aire y todo lo toca, todo lo conecta, todo lo simboliza. También Manuel Castells (2003 y 2006) plantea la sociedad contemporánea bajo la alegoría de la red. Este espíritu, propagado por las escrituras de todo el siglo $\mathrm{XX}$, sea cual fuere su soporte -pues entendemos escritura en el sentido más lato del término-, encuentra un nuevo impulso en el horizonte de una «mutación digital» (Broullón-Lozano, 2017) que promete imprevisibles consecuencias y apasionantes retos en torno a la condición del "cibertexto» electrónico, en virtud de un software (Manovich, 2013) o cara visible, legible y navegable, que permite manejar la ingente acumulación de materiales fragmentarios previamente clasificados en una base de datos (Bulajic, 2007).

Ante semejante coyuntura, el presente trabajo plantea un estudio comparatista entre escrituras literarias y audiovisuales en un eje diacrónico, a partir de la contraposición de dos series históricas que relacionen el sistema global con el ámbito hispánico. De un lado, la escritura exploratoria y cooperativa Hypertext Hotel (1992) (http://www.hypertext.international/) -impulsada por Robert Coover con estudiantes de escritura creativa de la Universidad de Brown en un servidor MOO- y la obra coordinada por el Colectivo Juan de Madre y publicada por la editorial Aristas Martínez en 2017 Leyenda mayor de Ian Curtis; de la otra, la experiencia polifónica de dos films españoles y digitales recientes: +101 (Cine sin Autor, 2012) y Quién lo impide (Jonás Trueba, 2018), en conexión con sus precedentes en el cine europeo de no-ficción.

\section{CONCEPTUALIZACIÓN: ERGODICIDAD, CIBERTEXTO, HIPERTEXTO E HIPERFICCIÓN CONSTRUCTIVA}

Partiendo del concepto de 'ergodicidad' (Aarseth, 1997 y 2004), deduciremos las restantes nociones esenciales para este estudio. El neologismo ergódico/a contiene las raíces griegas Epүoৎ -ergos: 'trabajo', 'acción'- y òdó -odos: 'camino', 'viaje', 'ruta'. Lo ergódico designa cierto trabajo o esfuerzo requerido al lector o a la audiencia -al receptor en definitiva, si nos apoyamos en el modelo de la comunicación poética de Roman Jakobson (1982: 347-395)-, a la hora 
de enfrentarse a la decodificación e interpretación de una obra. En este contexto la literatura ergódica no apunta tanto a una tipología textual como a una forma de entender la interacción entre el receptor y el mensaje. Se trata de una interacción con un alto grado de compromiso y participación por parte del primero, Ilegando incluso al esfuerzo físico. El engagement que se establece puede, de acuerdo con Edward J. Maloney (2005: 156), producir múltiples sentidos alternativos, dependiendo de qué componente, si el mimético o el sintético, quede resaltado en la interacción. Aquel texto que muestre una mayor preocupación por los componentes sintéticos exigirá un movimiento especialmente complejo por parte del receptor.

El mensaje textual que solicita dicho compromiso se conoce como cibertexto: una categoría textual que, como vemos, no está necesariamente ligada al ámbito electrónico ni a la tecnología de la información - «cybertext, then, is not a 'new', 'revolutionary' form of text, with capabilities only made possible through the invention of the digital computer. Neither is it a radical break with old-fashioned textuality, although it would be easy to make it appear so" (Aarseth, 1997: 18)-, antes bien, se relaciona con la comunicación poética y con aquella forma de interacción que propone la teoría de la recepción (Warning, 1989):

A perspective on all forms of textuality, a way to expand the scope of literary studies to include phenomena that today are perceived as outside of, or marginalized by, the field of literature -or even in opposition to it, for -as I make clear later-purely extraneous reasons (Aarseth, 1997:18).

Con el mensaje y con el emisor, también cambia el receptor. Así,

[...] el papel del nuevo lector no-secuencial parece revalorizado: él es quien decide, de forma que puede, por ejemplo, abandonar el texto principal en favor de otros y establecer asociaciones entre ellos (Martínez Fernández, 2001: 195).

El siguiente término, solidario con el anterior, es el de hipertextualidad, en su doble acepción. La primera de ellas es la señalada por Gérard Genette (1988: 1415) como funcionamiento textual trascendente entre un "hipotexto $A$ " preexistente -que sirve de fondo- $y$ un nuevo "hipertexto B", que viene al frente, renovado. La hipertextualidad, en casos como los de la parodia o la transcodificación genérica, solicita, pues, la complicidad del receptor, quien ha de contar con la competencia suficiente como para conectar unidades él mismo, decodificar y establecer niveles de lectura.
En una segunda acepción del hipertexto, fue Vanevar Bush quien usó por primera vez el término en 1945, al describir el memex, un dispositivo capaz de almacenar cantidades ingentes de información a las que cualquier usuario podría acceder estableciendo relaciones entre las diferentes unidades -fueran textos lingüísticos o ilustraciones- e interviniendo sobre ellas. Ted Nelson ${ }^{1}$, entendiendo el hipertexto como "una red semántica de conocimiento» (Martínez Fernández, 2001: 194), lo definiría en 1965 como

A body of written or pictorial material interconnected in such a complex way that it could not conveniently be presented or represented on paper. It may contain summaries, or maps of its contents and their interrelations; it may contain annotations, additions and footnotes from scholars who have examined it (Nelson, 1965: 96; cfr. Aarseth, 1997: 12-13; Pajares Tosca, 1997).

Desde esta perspectiva, tampoco podemos restringir el hipertexto al ámbito de la escritura narrativa, pues textos cuya narratividad es prácticamente nula, como el I Ching o Libro de las mutaciones ${ }^{2}$, o las series pictóricas, bien pueden considerarse como hipertextuales.

En términos espaciales, los soportes de comunicación basados en las tecnologías de la modernidad -el papel impreso o la proyección secuencial de imágenes- permitían únicamente la linealidad. Así pues, en cuanto a la exposición de ideas, tienen limitaciones. Por el contrario, es la tecnología digital la que hace posible la utilización de un medio que convoque a un tipo de receptor distinto. Este nuevo medio «will let the reader find his level, suit his tastes and find the parts that take on special meaning for him, as instruction or entertainment» (Nelson, 1965: 96). En dicho medio tendrían también cabida textos no-lingüísticos, como el icónico -fijo o en movimiento- o el auditivo ${ }^{3}$ -siendo estos últimos elementos no-lineales ${ }^{4}$-. Hablamos entonces de un sistema hipermediático, intermedial o transdiscursivo -dependiendo de la relación entre los materiales-, que encontraría su sistema de distribución -siempre en opinión de Nelson- en un soporte electrónico o digital, el único capaz de integrar materiales heterogéneos en una compleja y masiva red sin la intervención directa del agente humano. Es por tanto un soporte trans-humano, pues va más allá de los límites, capacidades y acciones ejecutadas por el homo sapiens sapiens. Y ello, como veremos, pone en jaque a la figura autoral.

Tales posibilidades se han aprovechado para la creación de ficciones, que en este medio tomarían el nombre de hiperficciones. Uno de los recursos esenciales 
del hipertexto es el hyperlink o hipervínculo -vínculo o link, para abreviar-, que posibilita la ruptura de la linealidad en el hipertexto ${ }^{5}$. Podemos entender estos links como coordinadores o nexos electrónicos que se encargan de unir lexías tanto externas como internas a una obra, dando lugar a un texto experimentado como no-lineal, multilineal o multisecuencial (citado en Pajares Tosca, 1997). Esto se traduce en una potencialmente infinita cantidad de realizaciones alternativas dentro del mismo argumento. Sin embargo, las secuencias aisladas, realizadas mediante la recepción ergódica del hipertexto narrativo, sí son lineales. Es la navegación entre secuencias en el hipertexto -en su recepción ergódica- la que posibilita, como es evidente, su combinatoria. Por otro lado, la hiperficción constructiva posee una intención en ocasiones lúdica, no resultando tan importante el producto como el proceso de construcción.

Finalmente, las hiperficciones pueden generar relaciones desestabilizadoras y conflictivas. El prefijo hiper-, como vínculo, y el carácter ergódico del cibertexto, en tanto que llamada al compromiso del receptor, pueden suscitar un nivel de lectura añadido, que llamaremos reflexivo, en tanto que generan una fricción en el estatuto mismo de las unidades textuales, en su verosimilitud o credibilidad, devolviendo una imagen irónica o cuestionadora al receptor. Veremos que estos procesos de ficcionalidad reflexiva traen consigo importantes consecuencias.

\section{HIPERFICCIÓN CONSTRUCTIVA EN LA LITERATURA CONTEMPORÁNEA}

A pesar de que Nelson limitaba el concepto de hipertexto al ámbito de la tecnología digital, existen modelos anteriores. Cabría mencionar cualquier obra en la que «las notas al margen dan la posibilidad de crear redes narrativas [...], dando lugar a caminos alternativos en la narración y eliminando la posibilidad de una progresión sucesiva» (Romero-Santos, 2017: 275), caso de El beso de la mujer araña (Manuel Puig, 1976), Infinite Jest (David Foster Wallace, 1996) o Pale Fire (Vladimir Nabokov, 1962), además de otras más claramente hipertextuales, como House of Leaves (Mark Z. Danielewski, 2000). En estos casos, el superíndice del texto principal, que remite a una nota al pie o al margen, funcionaría como un primitivo hipervínculo. Pero fue el espacio informático virtual lo que propició la aparición de obras como las que ideó Michael Joyce a partir de 1987: la considerada como primera obra literaria hipertextual, Afternoon: a story, publicada en 1990, tres años después de su escritura; o Twilight: A Symphony
(1996). Otros ejemplos de narrativa hipertextual en esa época son Victory Garden (Stuart Moulthrop, 1992), Patchwork Girl (Shelley Jackson, 1995) o Marble Springs (Deena Larsen, 1993), un poema narrativo, en este caso. Todos estos ejemplos fueron creados a través de Storyspace, un software diseñado en 1987 por el propio Joyce y David Jay Bolter precisamente para la escritura y lectura de hiperficciones.

Estas hipernarraciones caben, pues, dentro del concepto de escritura electrónica para ser experimentada a través de las mismas herramientas ${ }^{6}$. Pero si las anteriores constituían experiencias de hiperficción explorativa, entonces surge, por oposición, el concepto de hiperficción constructiva, a propuesta de Michael Joyce. En cuanto a su autoría, la hiperficción explorativa no precisa más que un escritor, al contrario de lo que ocurre con la constructiva, en donde se encomienda al lector o «experimentador de ficción» el trabajo de transitar el laberinto hipertextual elaborado por un tercero, «borrándo[se] los límites autor-lector» (Pajares Tosca, 1997). En este punto, según Pajares Tosca (1997) (véase también Franco y García Rueda, 2000), existe un antecedente en los juegos de rol tradicionales, de mesa o pen-and-paper, en los que un moderador o máster actúa como narrador principal de una historia cuyos personajes son interpretados por los demás participantes, que intervienen con sus actuaciones, es decir, con sus narraciones particulares, en la historia principal. También han de señalarse los llamados MUDs (multi-user dungeons), creación de Roy Trubshaw y Richard Bartle, programadores de la Universidad de Essex. Inspirados por los videojuegos Colossal Cave Adventure (1976) y el clásico Zork (1977) -que estaban diseñados para un solo jugador-, los MUDs son videojuegos de rol en línea basados en textos, en los que pueden participar varios jugadores interviniendo con sus performances particulares en una historia que no tiene ni un principio ni un final claros (Aarseth, 1997: 13).

Dicho esto, la mayor parte de las obras mencionadas hasta ahora caen bajo la denominación de hiperficción explorativa. Cabe señalar que ciertas obras que consideramos hiperficciones constructivas son al mismo tiempo explorativas, al menos en la fase de confrontación con el lector. Los ejemplos puros de hiperficción constructiva son por tanto más escasos. En cualquier caso, existen grandes bases de datos en Internet a disposición del usuario, como la organizada por el CELL (Consortium on Electronic Literature) Project (http://cellproject.net/), que incluyen una inmensa cantidad de ejemplos de literatura electrónica de libre consulta. 


\subsection{Un hotel edificado en el tercer entorno}

En 1990, el estadounidense Robert Coover dirigió un Taller de Ficción Hipertextual en la Universidad de Brown: "a course devoted as much to the changing of reading habits as to the creation of new narratives» (Coover, 1992). Cada semestre, a cada uno de los diecisiete alumnos matriculados se le asignaban diez megabytes de espacio digital en el clúster de servidores de la universidad para crear sus hiperficciones individuales con ayuda del software Storyspace, en paralelo a la creación de una hiperficción colectiva denominada Hypertext Hotel. Esta segunda actividad, que se desarrolló en un servidor $\mathrm{MOO}^{7}$, consistía en la creación de una ficción contextualizada en un hotel ficticio y virtual (Coover, 1992) ${ }^{8}$. Este hotel tenía continuidad a lo largo de sucesivas ediciones del taller. Todos los cursos, Coover y sus alumnos volvían a explorar las habitaciones configuradas por las promociones precedentes, introduciendo nuevas situaciones y personajes. También participaron autores externos, como demostraba su libro de visitas. Dichas contribuciones eran tanto creativas como destructivas: desde la aparición de una nueva habitación o personaje hasta el asesinato o ruptura de una relación amorosa previamente establecida. Como resultado, "the environment was set to anarchic, creative chaos, a wild place to stay where there was no promises, no expectations, and no order beyond the limits of the software» (Cutrona, 2018).

De esta experiencia Coover dedujo una preocupación especial por la estructura, más que por otros elementos de la narración como pueden ser el argumento o los personajes. Cuando nos referimos a la estructura de la ficción hipertextual estamos hablando en realidad de un laberinto surgido de la interconectividad y multidireccionalidad dada por el uso del hiperlink: "the most radical new element that comes to the fore in hypertext is the system of multidirectional and often labyrinthine linkages we are invited or obliged to create» (Coover, 1992). Y es en el espacio propiciado por los nexos del hipertexto donde ocurre gran parte de la experiencia de lectura: "the text fragments are like stepping stones, there for our safety, but the real current of the narratives runs between them» (Coover, 1992). El sentido de la narración se deriva, pues, de los huecos semánticos que constituyen los links: horizontes de posibilidades. El link es el umbral al abanico de realizaciones posibles de la ficción. Ello plantea nuevos problemas, el del flujo narrativo y la clausura de la obra, que pueden resumirse en la pregunta de Coover (1992): "how do you move around in infinity without getting lost?». Efectivamente, el laberinto virtual puede llegar a confundir y extenuar al lector, incapaz de encontrar una lectura canónica, al carecer el texto de un único principio, un único nudo y un único final. Así, la clausura del texto es, por su inexistencia, insatisfactoria.

Nos hemos referido a este hotel virtual en tiempo pasado. Lamentablemente, y a pesar de lo que expresaba Robert Coover en su artículo de 1992 The End of Books - «I would like to see it stay open for a century or two»-, el hotel hipertextual lleva más de veinte años clausurado. Era esta una de las preocupaciones de Coover ante un nuevo medio y paradigma en el que las generaciones informáticas se suceden sin pausa, en una vertiginosa dinámica evolutiva (Coover, 1992). Pero afortunadamente, gracias a un equipo de estudiantes de Southern Oregon University, liderados por el profesor Robert Arellano -autor de la hiperficción Sunshine'69 (1996)-, está en marcha un proyecto para recuperarlo (http://www. hypertext.international).

\subsection{La Leyenda híbrida de lan Curtis}

El segundo modelo literario que vamos a analizar es la obra del Colectivo Juan de Madre ${ }^{9}$ Leyenda mayor de lan Curtis (2017). Si bien no sigue un patrón hipertextual completo, pues está recogida en formato de libro, resulta especialmente relevante por su modus operandi híbrido en pleno apogeo digital. La obra está dividida en siete secciones, incluyendo cada una de ellas una serie de "ecos» ocasionalmente acompañados de imágenes u otros documentos visuales, con los que se reformula, apoyándose en referencias culturales concretas, la biografía del fallecido vocalista de Joy Division lan Curtis, dando lugar así a una biografía mítica y alternativa ${ }^{10}$ a la histórica. El carácter de leyenda mayor es decididamente experimental, y pretende la construcción de una ficción expansiva: «tienes en tus manos el texto fundacional de los humanos monocordes: la hagiografía expansiva de lan Curtis...» -reza el texto de la contraportada-. En el prefacio también queda explicado que

[...] las poseedoras de este volumen quedan invitadas a completar con sus propios ecos los agujeros blancos que lo atraviesan. Ecos de vuestras propias vidas, o de aquellas que os acompañan.

Podéis hacerlo manuscribiendo pasajes propios o ajenos directamente sobre el artefacto de papel que 
ahora mismo sujetáis entre vuestras manos, que son las manos de lan Curtis; guardando en la intimidad vuestra trenza.

Pero, si deseáis ser cómplices de la multiplicación de esta hagiografía, ampliando futuras ediciones, queda a vuestra disposición el siguiente sitio web: www.humanosmonocordes.com

\section{Gritad ahí vuestros ecos.}

Se convertirán en cuentas de este collar infinito (Colectivo Juan de Madre, 2017a: 139).

Nos llama la atención la libertad ofrecida al lectorcolaborador, mediante muy acertadas denominaciones que concuerdan perfectamente con la cooperación del lector de la que hablan las teorías de la recepción. Ello sugiere dos posibilidades de interacción con la obra: una secreta y personal que toma la forma de manuscrito dentro del propio volumen físico ${ }^{11}$-rellenar los «agujeros blancos»- y otra cómplice y abiertamente colaborativa que da al lector la potestad de ser paralelamente autor de «este collar infinito» -otra clave de la hiperficción-, incluyendo sus contribuciones o «ecos» en la web referida. Esto convertiría Leyenda mayor de lan Curtis en una obra de ficción constructiva y analógica con Internet como aparato auxiliar ${ }^{12}$.

En el mismo prefacio, siempre bajo la máscara de la ficción, se justifica el mecanismo colaborativo basado en la posibilidad de su ampliación a través de agentes externos. Así, a los coescritores se les identifica con sectarios miembros de la hermandad de los humanos monocordes, de la cual existirían células diseminadas por todo el mundo -las más importantes en Barcelona y Sevilla-, y cuyo objeto de veneración sería el Ian Curtis mistificado del que hablábamos. El coordinador semificticio del volumen se hace llamar Manuela Buriel -quien probablemente no sea otro que el Colectivo Juan de Madre (Palao, 2015: 48), lo que contribuye a la imagen de una autoría líquida.

Al día de esta publicación la web se halla inoperativa y no existen noticias de una edición posterior a la primera de $2017^{13}$. Sin embargo, intentos como este de resistencia a un horizonte literario exclusivamente digital divisado desde el tercer entorno, sin renunciar por ello a las bondades de la construcción colaborativa, de la narración no-secuencial, multiversal y constantemente provisional, dan noticia de la buena salud de que goza el matrimonio establecido desde hace largo tiempo entre la tradición más formal y la experimentación más subversiva en el ámbito de la literatura escrita.

\section{HIPERFICCIÓN CONSTRUCTIVA EN EL AUDIOVI- SUAL CONTEMPORÁNEO}

Es cierto que toda película en soporte de exhibición proyectable es lineal por su propia naturaleza. Por ello, y a priori, una película difícilmente podría considerarse como "ergódica», puesto que requeriría que los espectadores tuvieran la capacidad efectiva de elegir cuál será la secuencia siguiente en el montaje. Sin embargo, ya la película de ensayismo fílmico Chronique d'un eté (Jean Rouch y Edgar Morin, 1961), planteó un importante precedente predigital, por su carácter sintético antes que mimético. Ello demuestra que el audiovisual puede llegar a ser ergódico en tanto que problematice la forma del mensaje, solicitando al receptor que realice su propia síntesis final, que imagine lo que se oculta en las elipsis, que tome decisiones interpretativas, o mediante los finales abiertos. Ello se convertirá en un principio moral de cierta creación audiovisual contemporánea, pero resulta obligado incidir en el precedente de Chronique d'un été, pues se ubica en el seno de los planteamientos filosóficos situacionistas del siglo $X X$, por los que la realidad social depende de unas condiciones de posibilidad concretas, pactadas y enunciadas mediante actos performativos particulares. En consecuencia, una intervención singular de un sujeto o de un grupo social podría modificar como en el juego de rol o en el MUD- todo el conjunto de la historia. El modelo de múltiples narrativas situadas en los límites de la no-ficción que de aquí se deriva establece las categorías fundamentales de las obras que analizaremos a continuación: la muerte del autor, la forma dialógica y el carácter exploratorio, ya preconizado en el ensayismo fílmico de Rouch y Morin (Lopate, 1996; Montero, 2012).

\subsection{La muerte del autor}

En la estela de la muerte del autor decretada por Michel Foucault (1998: 35-71) y ratificada por Roland Barthes (2002: 73-82) desde finales del siglo XX, esta premisa dará nombre a uno de los colectivos más interesantes del panorama contemporáneo: Cine sin autor. La sinautoría consiste en una escritura cinematográfica -o audiovisual, en un sentido amplio- en la que «todas las personas que participan [...] son dueñas de las decisiones que se toman y donde la autoridad creativa y organizativa va circulando según las necesidades de lo que se produce» (Tuduri, 2008: 21 ss.). Este fenómeno tiene su base material en la tecnología digital, cuya capacidad de registro prácticamente ilimitada, ligereza -frente a los pesados equipos ana- 
lógicos- y bajo coste económico permiten las condiciones organizativas adecuadas para el pensamiento hipertextual:

Ahora tenemos masivamente en las manos las herramientas con las que se realiza: una cámara y un sistema portátil de edición y proyección. [...] Podemos organizarnos en torno a la producción de nuestras películas. Eso está demostrado. Solo hay que decidirlo, encontrarle el sentido social y político y tener un modelo preciso para que eso se pueda producir" (Tuduri, 2012: 125).

¿Qué forma simbólica puede surgir de una escritura que ha perdido su identidad autoral individual y su caligrafía (en un sentido estético)? Será un hipertexto colaborativo, haciendo gala de su producción colectiva y, en ocasiones, también tensiva y dialéctica entre todas las voces que entran en liza. Una forma que podríamos denominar, desde la teoría de la literatura, como "dialógica», en un sentido bajtiniano (Bajtin, 1982 y 1989), frente a la estética monologal de la escritura cinematográfica autoral y clásica.

\subsection{Forma dialógica}

+101 (Cine sin Autor, 2012) podría considerarse como la película fundacional de la sinautoría, tras su estreno en el año 2012 bajo el lema «iPara saber hay que imaginarse!». Según indica su sinopsis, se trata de un mediometraje de alrededor de sesenta minutos, producido y realizado por un grupo de jóvenes del Centro de Educación de Personas Adultas (CEPA), en el barrio madrileño de Tetuán. Tal argumento es lo primero que veremos en el metraje: los jóvenes se filman unos a otros, sus desplazamientos cotidianos, sus tiempos muertos conversando sobre cuestiones intrascendentes... (00:00:35). La vida se convierte en tema, al menos en un comienzo, porque muy poco después, primero mediante entrevistas -como las del cinéma vérité de Jean Rouch-, o luego reunidos en asamblea, debaten sobre las imágenes con las que conviven: aquellas que les inspiran (00:03:40), también aquellas que desearían producir ellos mismos en una película que planean realizar entre todos y que acuerdan titular La venganza (00:11:55).

A partir de aquí es cuando entra en juego la «hiperficción colaborativa», sea como estructura, sea como contenido fílmico: en +101 los jóvenes son los responsables de producir las escenas de ficción de La venganza a partir de una hipotética situación cotidiana: ¿cómo va a llegar la chica hasta la fiesta?, ¿ será allí objeto de deseo, o víctima de violencia? (00:12:23). De este modo la estructura de la película es plenamente hipertextual, al modo de las muñecas rusas, en tanto que primero se pactan las escenas, luego las visualizaremos según los acuerdos alcanzados, y finalmente nuevas declaraciones a cámara de los jóvenes creadores explorarán esas mismas escenas producidas y mostradas. Así es que la pluralidad de voces contrapone puntos de vista acerca de las situaciones, al tiempo que ficcionaliza comportamientos y prácticas cotidianas: «¿Es posible una relación de miradas entre un DJ que está a toda hostia y una chica que esté ahí? - No sé, es un poco extraño... [...] La escena vale pero no está bien hecha entonces» (00:32:00).

Si Jean Rouch reunía a sus colaboradores al final de su película en la sala de proyección para debatir sobre la credibilidad de las imágenes, Cine sin autor va más allá: extiende esa polifonía durante todo el metraje, de modo que las imágenes contenidas en el inconsciente colectivo de los jóvenes pasan a enjuiciarse gracias a las escenas hiperficcionales que las realizan. La escritura cinematográfica deviene una técnica privilegiada para ejercer la reflexividad a partir del diálogo con las unidades que componen el cibertexto audiovisual colaborativo. Si Bajtin entendía la «dialogía» o "dialogismo» como el principio constructivo del discurso narrativo a partir de la palabra, podría afirmarse que en esta forma simbólica hipertextual el debate sobre las imágenes que recorre toda la película responde a idéntico proyecto:

[...] Existen relaciones dialógicas, es decir, se oponen de acuerdo con las reglas de contrapunto. Es que las relaciones dialógicas representan un fenómeno mucho más extenso que las relaciones entre las réplicas del diálogo estructuralmente expresado, son un fenómeno casi universal que penetra todo discurso humano y todos los nexos y manifestaciones de la vida humana en general, todo aquello que tiene sentido y significado. [...] Donde empieza la conciencia, allí se inicia un diálogo (Bajtin, 1989: 67-68).

De forma análoga, para la sinautoría, dejar pasar esos elementos que nos recorren, acaso de una forma conflictiva, implica aceptar que «vivimos atravesados por flujos, corrientes, circulaciones de todo tipo de materias y materiales -afectivos, químicos, líquidos, mentales, ideológicos, sentimentales, orgánicos, relacionales, eléctricos, licuosos, armamentísticos, intelectuales, etc.» (Tuduri, 2008: 32). En +101 (00:54:00), el contenido de las ficciones, de las puestas en escena o dramatizaciones pasa, pues, a un segundo plano. Lo que parecía ser un making off de una película francamente amateur titulada La venganza se convierte en 
la película misma, abierta a la discusión con los espectadores, identificados y proyectados sobre el prolongado debate entre sus creadores y las imágenes culturales que los atraviesan.

\subsection{Negociación de sentido: de la narración lineal al cibertexto como hiperficción explorativa}

Nos interesa en este punto el concepto mismo de "escritura colaborativa» en tanto que, tematizado en el texto fílmico -o cibertexto audiovisual-, puede volver del revés la ficción, proponiendo un ejercicio de reflexividad. Bajo este punto de vista, la cooperación a la construcción discursiva del receptor implica una dimensión ética, ya que las imágenes y sonidos de la escritura audiovisual son solo el principio, un primer estímulo. Desde este momento, la teoría del cine habla de un "espectador emancipado» (Rancière, 2010), el cual aparece invocado en la estructura o "fábula» del texto audiovisual (Rancière, 2005). Mas esta figuración es ausente o inducida, en virtud de las zonas de indeterminación que aparecen en el tejido fílmico, cuando no directamente vacíos semánticos: si en el Leyenda mayor de lan Curtis se hablaba de «agujeros blancos", haciendo referencia a los espacios vacíos en el discurso, mucho más allá de los huecos sobre el papel, en el audiovisual bien podemos hablar de «agujeros negros», aludiendo a los fundidos en negro que puntúan las elipsis entre escenas, ocultando el desenlace y exigiendo que el espectador imagine lo que ha sucedido entre una imagen y la siguiente.

El cibertexto audiovisual se caracterizará, pues, por su ausencia de clausura, por su carácter non finito, de modo que al "espectador emancipado» se le transfiere la responsabilidad de negociar un sentido con significantes fragmentarios, heterogéneos y a menudo ambiguos. Rancière plantea al espectador emancipado a partir de una tensión entre lo que "sabe-que-sabe» y lo que "descubre que todavía ignora», en un permanente movimiento de ida y vuelta, como corresponde al movimiento ergódico. Y ello resulta profundamente ético, puesto que exige una dinámica de relación que reconozca al sujeto como un individuo dotado, ante todo, de inteligencia: «la emancipación intelectual es la verificación de la igualdad de todas las inteligencias» (Rancière, 2010: 17).

En la trayectoria de Jonás Trueba, la clase de provocaciones que invocan a un «espectador emancipado» -o «iluso», en palabras del propio Trueba- se puede señalar en torno al concepto de 'entretiempo' como significante básico de sus películas. El entretiempo como estar entre las cosas, in between, a la espera:
[...] cuando coges un avión, lo único que parece interesar es el destino. El trayecto entre el lugar que estás dejando atrás y el destino parece que no cuenta. Sin embargo, en esa especie de limbo que es un viaje en avión, te encuentras en un tiempo abstracto, en el que puedes disfrutar de una emoción particular, en la que surgen ideas (citado en Broullón-Lozano, 2015: 23).

Se trata de una suerte de iconoclastia con respecto a la escritura cinematográfica clásica, narrativa y causal, que convoca la mirada escrutadora del espectador como cooperante necesario: «no puedo poner orden donde no hay historia. Me contento con ir acumulando notas, sigo escribiendo imágenes, diálogos... el orden se impondrá después»-comenta Trueba sobre su método de escritura fílmica (citado en BroullónLozano, 2015: 34)-.

La escritura de Trueba muestra los vínculos más que los lugares de partida y llegada -o «causas» y «efectos»-, cuyas múltiples figuraciones quedan a cargo de la imaginación del receptor. En películas como Los ilusos (2013), Los exiliados románticos (2015), La reconquista (2017) o La Virgen de agosto (2019), en donde todavía es fuerte la presencia del cineasta como autor, la continuidad narrativa del relato tiende a diluirse entre los entretiempos -elipsis, silencios y vacíos: «agujeros negros»- y los diálogos de los personajes -frecuentemente, en desacuerdo entre ellos. El texto resultante es, pues, de carácter exploratorio en su forma y constructivo en la recepción.

En la experiencia de Quién lo impide (2018), Trueba va más allá, ya que emplea unas condiciones de producción colaborativas, en donde da un paso atrás como autor, mediante un taller de cine con adolescentes que se convierte en la premisa para un resultado múltiple: en su montaje final, Quién lo impide consta de cuatro piezas, a saber: Solo somos (90 minutos), Principiantes (60 minutos), Si vamos 28, volvemos 28 (80 minutos) y Tú también lo has vivido (55 minutos). En ellas la palabra dialogada como contraste o dialogía -en las entrevistas testimoniales de Solo somos o Tú también lo has vivido- son el primer paso para reflexionar acerca de las representaciones de los sujetos participantes y el pacto tanto de un tipo de escritura fílmica como de una serie de ficciones -como la hipotética ficción amorosa de Solo somos- que ponen en tela de juicio esas mismas representaciones iconográficas en el inconsciente colectivo con las que se ha negociado desde un principio. Cuatro unidades textuales que ya no son nada pequeñas, pero que crean entre todas una estructura hipertextual colaborativa sin continuidades rígidas, más allá del orden aleatorio 
que la proyección le quiera otorgar. Pero, sobre todo, es un conjunto en donde se inscribe el proceso de escritura como principio de una negociación de sentido con los materiales acumulados y presentados:

Me daba cuenta de que el verdadero interés y alcance de todo este proyecto pasaba por intentar construir nuevos marcos de acción, de rodajes y registros cinematográficos, ficcionales o documentales, pero también de difusión, exhibición y reflexión, con la intención de seguir compartiendo el cine y la vida, ahora con la certidumbre clara de que estábamos ante un reto mayor, un proyecto cinematográfico, audiovisual y multidisciplinar, que iba a prolongarse en el tiempo y cuyo valor genuino era precisamente su forma de expandirse en diferentes formatos $y$ en diversos ámbitos, así como nuestra capacidad de adaptarnos a todo ello, permaneciendo atentos y generosos (Trueba, 2019).

En definitiva, esta experiencia propone un interesante marco para la escritura audiovisual en virtud de la capacidad de registro de imágenes y sonidos de los dispositivos técnicos y de los principios éticos y estéticos de la «dialogía»-que sustituye a la «autoría»- y del «espectador emancipado»-o del «iluso»- como puntos de partida para un debate abierto, en lo cual deviene el acto de proyección. Y es que Quién lo impide no puede verse completa en Internet. Los Ilusos Films emplea un sistema de distribución co-presencial que exige de la reunión interpersonal que propicie el debate y la discusión, como los festivales de cine, los cinefórum o los cines de verano, modalidad que emplean frecuentemente, lo que devuelve al texto del mundo digital al mundo encarnado de la vida.

\section{CONCLUSIONES}

La forma simbólica y el espacio social que propician este tipo de escrituras arrojan importantes consecuencias sobre los modos de escribir, pero también de relacionarnos con los textos, sea cual sea su soporte. De manera sistemática, las reuniremos en cinco puntos:

1. Los objetos descritos demuestran la importancia de la tecnología para revitalizar las posibilidades del cibertexto y de la hipertextualidad, con importantes precedentes en las escrituras analógicas. La tecnología electrónica y digital, con sus estructuras reticulares, conecta todo tipo de materiales en estado de disponibilidad latente en las bases de datos o servidores. Así pues, la exploración de aquellos materiales o navegación gracias a un software, inscribe múltiples recorridos o discur- sos posibles, que pueden coexistir simultáneamente, o bien borrarse, reescribirse, reformularse, cuantas veces se desee.

2. Este conjunto de prácticas entraña implicaciones epistemológicas que no pueden soslayarse, pues afectan al modo en que gestionamos la información y construimos la imagen de la realidad como red de relaciones. El cibertexto y la hipertextualidad descubren un cambio sustancial en las formas simbólicas contemporáneas, pues formulan un tipo de racionalidad conectiva capaz de negociar con la complejidad, con lo multiforme, e incluso con lo contradictorio, a través de la exploración múltiple.

3. Implicaciones estéticas: emerge un paradigma colaborativo, una escritura en la que el estilo monologal de la autoría moderna da lugar a una polifonía, o bien situada como premisa de la producción de las escrituras -las escrituras a varias manos-, o bien en tanto que la instancia autoral acepta que está atravesada por voces y discursos, que conviene poner en tela de juicio mediante una actitud reflexiva.

4. Tres son las implicaciones éticas: a) estas escrituras reconocen el lugar y la capacidad de agencia del receptor-ergodicidad-; b) generan un espacio democrático de discusión, en lugar de un ámbito preceptivo, impositivo o, en el extremo, coercitivo tanto de las escrituras como de las interpretaciones; y c) su carácter reflexivo permite poner en tela de juicio los patrones y pautas que conforman el imaginario colectivo, que pasa a infiltrarse en la red de elementos que componen el repositorio o cibertexto en estado de disponibilidad, manipulando los nexos y objetivizando dichos patrones culturales como (hiper)ficciones realizadas.

5. Finalmente, se ponen de manifiesto las limitaciones del medio digital para alojar y preservar la obra de arte, como hemos visto en la desaparición de los hipertextos literarios o en la resistencia de Jonás Trueba a renunciar a los cines como espacio social en favor de Internet. Sin embargo, aparejado al fracaso de las expectativas generadas por el nuevo modelo tecnológico universal, lo cierto es que el factor humano regresa al frente, o bien para discutir esos materiales -como en el audiovisual contemporáneo- o bien para revitalizarlos y continuar la escritura en un proceso sin fin, lo que nuevamente nos habla de su permanente devenir. 


\section{NOTAS}

1. Nelson llegaría a desarrollar un proyecto de biblioteca universal, conocido como xanadu, accesible desde cualquier lugar del mundo.

2. El / Ching, libro oracular chino cuyos primeros textos datan del 1200 a. C. aproximadamente, «is not meant to be read from beginning to end but entails a very different and highly specialized ritual of perusal» (Aarseth, 1997: 2).

3. El término hyperfilm encuentra aquí todo su sentido.

4. En lo anterior seguimos a Nelson (1965: 96). Véase también Martínez (2001: 194) y Pajares Tosca (1997)

5. «La escritura en segunda dimensión es la contribución especial del medio electrónico a la historia de la literatura» (citado en Pajares Tosca, 1997).

6. Además de aunar organizaciones de estudio de literatura electrónica de todo el mundo, el sitio web de Consortium on Electronic Literature (CELL) ofrece una completa taxonomía para este tipo de literatura.

\section{REFERENCIAS}

Aarseth, Espen J. (1997). Cybertext. Perspectives on Ergodic Literature. Baltimore y Londres: The Johns Hopkins University Press.

Aarseth, Espen J. (2004). La literatura ergódica. En: Domingo Sánchez-Mesa Martínez (ed.). Literatura y Cibercultura. Madrid: Arco Libros, pp. 117145.

Bajtin, Mijail (1982). Estética de la creación verbal. México: Siglo XXI.

Bajtin, Mijail (1989). Teoría y estética de la novela. Madrid: Taurus.

Barroso Villar, M.a Elena (2007). Algunas perspectivas sobre el discurso literario y cuestiones conexas. Intersecciones de la teoría. En: Angélica Tornero (ed.). Discursare. Reflexiones sobre el discurso, el texto y la teoría de la literatura. Cuernavaca, México: Universidad Autónoma de Morelos, pp. 15-54.

Barthes, Roland (2002). El susurro del lenguaje: más allá de la palabra y la escritura. Barcelona: Paidós.

Bolter, David Jay y Grusin, Richard (2011). Inmediatez, hipermediación, re-mediación. CIC Cuadernos de Información y
7. MOO es un término conflictivo. Además del nombre del servidor creado en 1990 por el programador canadiense Stephen White, nombre que se recicló para los posteriores espacios virtuales basados en textos inspirados en el original, funciona como sigla de «MUD object-oriented» que significa en este caso Multi-User Domain, una derivación del ya referido Multi-User Dungeon. En ocasiones MOO y MUD además de MUSH y MUCK- se utilizan indistintamente para referirse al mismo concepto.

8. La inclusión de imágenes y archivos de audio convertía este hotel no solo en hipertextual, sino en hipermediático (Coover, 1992).

9. Todo parece indicar que Colectivo Juan de Madre es el pseudónimo de un autor colectivo.

10. Palao (2015: 50) habla del «multiverso secuencial de Juan de Madre».

11. En las páginas 140 y 141 existe una sección pautada con el título «notas»

Comunicación, 16: 29-57. https://doi. org/10.5209/rev_CIYC.2011.v16.2

Broullón-Lozano, Manuel A. (2015). Algunas claves de la poética de Los ilusos (Jonás Trueba, 2013): en torno al concepto de entretiempo. En: Virginia Guarinos Galán (coord.). Apuntes de cine. Homenaje a Rafael Utrera Macías. Madrid: Delta, pp. 15-26.

Broullón-Lozano, Manuel A. (2017). Poética y lógica del esbozo [Tesis doctoral]. Universidad de Sevilla: Sevilla. Disponible en: https://idus.us.es/handle/11441/70192 [Fecha de consulta: 27 octubre 2020].

Bulajic, Viktorija Vesna (2007). Database aesthetics art in the age of information overflow. Minneapolis: University of Minnesota Press.

Castells, Manuel (2003). La Galaxia Internet. Barcelona: Debolsillo.

Castells, Manuel (2006). La era de la información: economía, sociedad y cultura. Madrid: Alianza.

Cassirer, Ernst (1998). Filosofía de las formas simbólicas. México: Fondo de Cultura Económica. diseñada para que el lector escriba a mano sus «ecos». Lo mismo ocurre a lo largo del resto del libro, atravesado por secciones pautadas, en este caso sin el encabezado de «notas».

12. Véase Palao (2015: 47) y la descripción comercial de la Revista oficial del clan monocorde sevillano (Colectivo Juan de Madre, 2017b). Palao (2015:48) ve además en las novelas de Juan de Madre «un embrión de una teoría narrativa posthipertextual».

13. Casi pareciera que el Colectivo Juan de Madre, sabiendo efímero el espacio prestado por Internet, se curara en salud al ofrecer la opción de anotar directamente el volumen en formato físico. Extraemos el texto de un documento publicitario para uno de los talleres de los humanos monocordes: «Kit de montaje analógico para publicación. Incluye: - *Doce bancos de textos, imágenes y plantillas impresas en polímero de 90 gr. - *Un cuaderniIlo: 12 páginas con astralón impreso en papel ahuesado de 120 gr.».

Cine sin Autor (2012). +101. Disponible en: https://vimeo.com/channels/640261/67080122 [Fecha de consulta: 27 octubre 2020].

Colectivo Juan de Madre (2017a). Leyenda Mayor de lan Curtis. Badajoz: Aristas Martínez.

Colectivo Juan de Madre (2017b). Los humanos monocordes: revista oficial del clan monocorde sevillano. Badajoz: Aristas Martínez.

Coover, Robert (1992). The End of Books. The New York Times Disponible en: https://archive.nytimes.com/www.nytimes.com/books/98/09/27/specials/ coover-end.html [Fecha de consulta: 4 diciembre 2020].

Cutrona, Jim (2018). (Ongoing) Introduction: Hypertext Hotel Restoration. Disponible en: https://jimcutrona.wordpress.com/2018/04/28/ongoing-introduction-hypertext-hotel-restoration/ [Fecha de consulta: 27 octubre 2020].

Echeverría, Javier (2004). Telépolis y el tercer entorno. Barcelona: Destino.

Foucault, Michel (1998). ¿Qué es un autor? Litoral, 25/26: 35-71. 
Franco, Carolina y García Rueda, José Jesús (2000). Narrativa hipermediática: los nuevos contenidos para el cibermundo. Disponible en: https:// www.monografias.com/trabajos902/ narrativa-hipermediatica-nuevos/ narrativa-hipermediatica-nuevos.sht$\mathrm{ml}$ [Fecha de consulta: 4 diciembre 2020].

Genette, Gérard (1988). Palimpsestos. La literatura en segundo grado. Madrid: Taurus.

Jakobson, Roman (1982). Lingüística y poética. Barcelona: Seix Barral.

Lakoff, Georges (2007). No pienses en un elefante. Lenguaje y debate político. Madrid: Editorial Complutense.

Landow, George P. (2006). Hypertext 3.0: critical theory and new media in an era of globalization. Baltimore: John Hopkins University Press.

Lopate, Phillip (1996). In Search of the Centaur: The Essay-Film. En: Charles Warren (ed.). Beyond Document. Essays on Nonfiction films. Middletown: Wesleyan University, pp. 243-269.

Maloney, Edward J. (2005). Footnotes in Fiction: A Rhetorical Approach [Tesis doctoral]. The Ohio State University: Columbus.

Manovich, Lev (2013). Software takes command extending the language of the new media. Nueva York: Bloomsbury Academic.
Martínez Fernández, José Enrique (2001). La intertextualidad literaria: base teórica y práctica textual. Madrid: Catedra.

McLuhan, Marshall (1996). Comprender los medios. Las extensiones del ser humano. Barcelona: Paidós.

Montero, David (2012). Thinking images. The essay film as a dialogic form in European Cinema. Berna: Peter Lang. https://doi.org/10.3726/978-3-03530299-8

Nelson, Theodor H. (1965). A File Structure for the Complex, the Changing and the Indeterminate. Proceedings of the 1965 ACM 20th National Conference, pp. 84-100. https://doi. org/10.1145/800197.806036

Pajares Tosca, Susana (1997). Las posibilidades de la narrativa hipertextual. Revista de Estudios Literarios Espéculo, 6. Disponible en: http://pendientedemigracion.ucm.es/info/especulo/ numero6/s_pajare.htm [Fecha de consulta: 27 octubre 2020].

Palao, José Antonio (2015). Dar consigo no es ser: la disolución del sujeto en la novelística posthipertextual del Colectivo Juan de Madre. Revista de Estudios Literarios Espéculo, 54: 47-64.

Rancière, Jacques (2005). La fábula cinematográfica. Barcelona: Paidós.

Rancière, Jacques (2010). El espectador emancipado. Pontevedra: Ellago.
Romero-Santos, José Manuel (2017). Las notas al margen como recurso comunicativo en la producción literaria de David Foster Wallace. [Tesis doctoral]. Sevilla: Universidad de Sevilla. Disponible en: https://idus.us.es/handle/11441/77536 [Fecha de consulta 27 octubre 2020].

Sánchez-Mesa Martínez, Domingo (ed.) (2019). Narrativas transmediales. La metamorfosis del relato en los nuevos medios digitales. Barcelona: Gedisa.

Trueba, Jonás (2018). Quién lo impide. Una experiencia de cine inmersivo con jóvenes adolescentes. [S. I.]: Los Ilusos Films.

Trueba, Jonás (2019). Quién lo impide. Notas del director. Disponible en: https://www. losilusosfilms.com/quien-lo-impide [Fecha de consulta: 11 septiembre 2019].

Tuduri, Gerardo (2008). Manifiesto Cine sin autor. Realismo social extremo en el siglo XXI. Madrid: Centro de Documentación Crítica.

Tuduri, Gerardo (2012). La política de la colectividad: ideas derramadas. Madrid: Cine sin Autor

Vázquez Medel, Manuel Ángel (2003). El gran mediodía: sobre la Transhumanización. En: Rafael Morales Astola y Javier Rodríguez Fito (eds.). Pensar la gestión cultural en Andalucía. Huelva: Asociación de Gestores Culturales de Andalucía, pp. 26-44.

Warning, Rainer (comp.) (1989). Estética de la recepción. Madrid: Visor. 